\title{
Interleukin 1 Acts on Cultured Human Vascular Endothelium to Increase the Adhesion of Polymorphonuclear Leukocytes, Monocytes, and Related Leukocyte Cell Lines
}

\author{
Michael P. Bevilacqua, Jordan S. Pober, M. Elyse Wheeler, Ramzi S. Cotran, and Michael A. Gimbrone, Jr. \\ Vascular Pathophysiology Laboratory, Department of Pathology, Brigham and Women's Hospital and Harvard Medical School, \\ Boston, Massachusetts 02115
}

\begin{abstract}
Increased leukocyte adhesion to the endothelial lining of blood vessels is an essential event in inflammation and the pathogenesis of certain vascular diseases. We have studied the effect of interleukin 1 (IL-1), an inflammatory/immune mediator, on endothelial-leukocyte adhesion using quantitative in vitro assays. Selective pretreatment of cultured human umbilical vein endothelial monolayers with IL-1 $(5 \mathrm{U} / \mathrm{ml}, 4 \mathrm{~h})$ resulted in an 18.3 \pm 2.6 -fold increase in human peripheral blood polymorphonuclear leukocyte $(P M N)$ adhesion (mean \pm SEM, $n=16)$ and a 2.6 \pm 0.3 -fold increase in monocyte adhesion $(n=7)$ over basal levels. IL-1-treated endothelial monolayers also supported increased adhesion of the promyelocytic cell line $\mathrm{HL}-60$ and the monocytelike cell line U937 (33.0 \pm 6.0 -fold, $n=6$ and 4.9 \pm 0.5 fold, $n=15$, respectively). In contrast, selective IL-1 pretreatment of leukocytes, or the addition of IL-1 during the adhesion assay, did not alter endothelial-leukocyte adhesion. Conditioned medium from IL-1-treated endothelial cultures also did not promote leukocyte adhesion to untreated monolayers. IL-1 induction of endothelial adhesivity was concentration dependent (maximum, $10 \mathrm{U} / \mathrm{ml}$ ), time dependent (peak, 4-6 h), and reversible, was blocked by cycloheximide $(10 \mu \mathrm{g} / \mathrm{ml})$ or actinomycin D (5 $\mu \mathrm{g} / \mathrm{ml})$ but not by acetylsalicylic acid $(100 \mu \mathrm{M})$, and occurred without detectable endothelial cell damage. IL-1 treatment of SV40-transformed human endothelial cells and dermal fibroblasts did not increase their adhesivity for leukocytes. These data suggest that IL-1 can act selectively on human vascular endothelium to increase its adhesivity for circulating blood leukocytes, and thus to localize leukocyte-vessel wall interactions at sites of inflammation in vivo.
\end{abstract}

\section{Introduction}

Localized adhesion of peripheral blood leukocytes to the endothelial lining is essential for their egress from the vascular space under physiologic and pathologic conditions, and is a key event in the pathogenesis of certain vascular diseases. Enhanced polymorphonuclear leukocyte (PMN) margination characteristically occurs at sites of acute inflammation, whereas monocyte

Aspects of this work were presented at the 69th Annual Meeting of the Federation of American Societies for Experimental Biology, Anaheim, CA, April 1985.

Address reprint requests to Dr. Bevilacqua. 1985

Received for publication 8 April 1985 and in revised form 3 July

J. Clin. Invest.

(c) The American Society for Clinical Investigation, Inc.

$0021-9738 / 85 / 11 / 2003 / 09 \$ 1.00$

Volume 76, November 1985, 2003-2011 interactions with the microvasculature are observed more often in chronic inflammatory reactions (1-5). Focal attachment of monocytes to the endothelium also occurs in large arteries as an early event in the development of atherosclerotic lesions (69). Although it has long been appreciated that humoral mediators are involved in the regulation of endothelial-leukocyte interactions, the relative importance of the endothelial cell and the leukocyte as targets for these mediators has been a matter of controversy (5).

Recent in vitro studies with cultured vascular endothelium have provided new insights into the effects of inflammatory mediators on endothelial-leukocyte interactions $(4,5,10)$. In particular, it has been shown that chemotactic factors, such as purified complement components, formyl-methionyl-leucyl-phenylalanine and leukotriene $\mathbf{B}_{4}$, can augment the attachment of PMN to cultured endothelial monolayers (11-18). Certain of these studies suggest that formyl-methionyl-leucyl-phenylalanine and leukotriene $B_{4}$, at least in part, produce their effects on leukocyte adhesion via the endothelial cell $(12-14)$. Interestingly, cultured vessel wall cells themselves appear to produce various inflammatory mediators (19-26), and thus, potentially, may locally regulate endothelial-leukocyte adhesion. However, the relative significance of endothelial versus leukocyte responses, and the cellular mechanisms involved in their adhesion remain to be defined.

Our current studies have focused on inducible alterations in the surface properties of viable endothelium that promote increased endothelial-leukocyte adhesion. Specifically, we have examined the effects of human monocyte-derived interleukin 1 (IL-1), ${ }^{1}$ a multifunctional inflammatory mediator (27-31), on cultured human vascular endothelium. We previously have established $(32,33)$ that IL-1 can stimulate endothelial cell synthesis and surface expression of a tissue factorlike procoagulant activity. We now report that IL-1 also acts directly and selectively on human endothelial cells to increase dramatically the adhesivity of their surfaces for PMN, blood monocytes, and the related cell lines HL-60 and U937. The effect of IL-1 is shown to be concentration, time, and protein synthesis dependent. This endothelial cell directed action of IL-1 may be important in regulating leukocyte-vessel wall interactions at sites of inflammatory reactions in vivo.

\footnotetext{
Methods

Cell cultures. Human umbilical vein endothelial cells (HEC) were isolated from two to five cord segments, pooled, and grown in primary culture

1. Abbreviations used in this paper: BAEC, bovine aortic endothelial cell(s); FCS, fetal calf serum; HEC, human endothelial cell(s); IL-1 and IL-2, interleukin 1 and 2; LSM, lymphocyte separation medium; M199, Medium 199; RPMI, RPMI-1640 medium (Roswell Park Memorial Institute).
} 
using Medium 199 (M199, M. A. Bioproducts, Bethesda, MD) with 20\% fetal calf serum (FCS, Gibco Laboratories, Grand Island, NY) and antibiotics, as previously described (34). Several strains were serially passaged (1:3 split ratios) using M199-20\% FCS supplemented with endothelial cell growth factor $(50-100 \mu \mathrm{g} / \mathrm{ml}$; a gift of Dr. T. Maciag, Meloy Laboratories, Springfield, VA) and porcine intestinal heparin (50-100 $\mu \mathrm{g} /$ ml, Sigma Chemical Co., St. Louis, MO) (35) in Costar tissue culture flasks ( $75 \mathrm{~cm}^{2}$, Costar, Cambridge, MA) coated with purified fibronectin $\left(1 \mu \mathrm{g} / \mathrm{cm}^{2}\right.$ Meloy Laboratories) or 0.1\% gelatin (Bactogelatin 0143-02, Difco Laboratories, Detroit, MI). HEC strains were typically selected for experimental use at passage levels 2-4. Three strains of adult human saphenous vein endothelial cells (kindly provided by Dr. P. Libby, Tufts University Medical School, Boston, MA) were cultured essentially as described for HEC. A line of SV40-transformed HEC (SVHEC-F), previously established in this laboratory (36), was cultured in M199-10\% FCS. Bovine aortic endothelial cells (BAEC), isolated from calf thoracic aortas, were cultured in Dulbecco's modified Eagle's medium (M. A. Bioproducts) with $10 \%$ calf serum (34). A single strain (11-BAEC), was utilized at passages 10-30. Two strains of human dermal fibroblasts (AIF21 and X1F30, kindly provided by Dr. J. Rheinwald, Dana Farber Cancer Institute, Boston, MA) were maintained in M199-15\% FCS. For experimental use, each cell type was plated $\left(2-4 \times 10^{4}\right.$ cells/well) and grown to confluence (3-7 d) on 15-mm Thermanox plastic coverslips (Miles Scientific, Naperville, IL) which in the case of HEC cultures had been precoated with fibronectin $\left(1-5 \mu \mathrm{g} / \mathrm{cm}^{2}\right)$, in $16-\mathrm{mm}$ diam tissue culture wells (Cluster 24, Costar).

Isolation and radiolabeling of leukocytes. PMN monocytes, and erythrocytes were routinely isolated from anticoagulated (sodium citrate dextrose $1: 9, \mathrm{pH} 6.5$ ) whole blood collected by venipuncture from normal donors of both sexes. Platelet-rich plasma was removed after centrifugation $(1000 \mathrm{~g}, 3 \mathrm{~min}$ ) and the cell pellet diluted 1:3 with Hanks' balanced salt solution without calcium and magnesium (HBSS, M. A. Bioproducts). PMN and mononuclear leukocyte fractions were separated by centrifugation $(500 \mathrm{~g}, 40 \mathrm{~min}$ ) on lymphocyte separation medium (LSM, Litton Bionetics, Kensington, MD) according to the method of Boyüm (37). Suspensions of PMN (>95\% pure by Wright-Giemsa staining; and containing $<1 \%$ platelet contamination by phase-contrast microscopy) were prepared as described previously (38). Monocyte-enriched populations (78-88\% pure) were prepared from the mononuclear cell fraction by density gradient centrifugation on modified LSM after stepwise increases in osmolarity of the cell suspension according to the method of Recalde (39).

For certain experiments, monocytes were isolated from residual leukocytes in plateletpheresis preparations (obtained from Massachusetts Red Cross, Boston) by counterflow centrifugation elutriation (40). In brief, the mononuclear cell fraction was collected after centrifugation $(500 \mathrm{~g}, 20 \mathrm{~min}$ ) on standard LSM, washed, and resuspended in 10-20 $\mathrm{ml}$ of buffered $\mathrm{NaCl}(0.15 \mathrm{M}), \mathrm{pH} 7.7$, with $0.625 \%$ glucose and bovine serum albumin (BSA, Fraction V, Sigma Chemical Co.). The counterflow centrifugation elutriation was performed using a Beckman JE-6B rotor with a standard separation chamber mounted in a Beckman J2-21M centrifuge (Beckman Instruments, Inc., Palo Alto, CA). The leukocyte preparation was loaded into an external chamber and passed through the rotor $(2,000 \mathrm{rpm})$ at increasing flow rates established by a Masterflex pump (Cole-Parmer Instrument Co., Chicago, IL). Elutriation fractions containing $>90 \%$ monocytes were selected for experiments. Contaminating leukocytes were predominately $\mathrm{T}$ lymphocytes. The purity of the monocyte suspensions was determined using several criteria (40), including: (a) size, assessed with a Coulter cell counter, model ZF (Coulter Electronics, Hialeah, FL); (b) morphology, evaluated by phase-contrast microscopy, $(c)$ histochemical staining for nonspecific esterase activity; and $(d)$ indirect immunoperoxidase staining (kindly performed by Dr. G. Pinkus, Department of Pathology, Brigham and Women's Hospital) using a monoclonal antimonocyte antibody (MO-2, Bethesda Research Laboratories, Bethesda, MD) and antilymphocyte antibodies (T11 and B1, provided by Dr. L. Nadler, Dana Farber Cancer Institute) (41). Washed erythrocyte suspensions were prepared from anticoagulated blood after centrifugation and removal of the buffy coat layer. The monocytelike cell line U937 (kindly provided by Dr. C. Bianco, New York Blood Center, New York) and the promyelocytic cell line HL-60 (kindly provided by Dr. V. Kelley, Brigham and Women's Hospital) were cultured in RPMI-1640 medium with $25 \mathrm{mM}$ Hepes (RPMI, M. A. Bioproducts) and $10 \%$ FCS.

To facilitate the quantitation of their adherence, blood cells or the leukocyte cell lines were labeled with ${ }^{111}$ indium-oxine (" ${ }^{111}$ In, Amersham Corp., Arlington Heights, IL) (15), Briefly, washed cells were resuspended $\left(10^{7}\right.$ cells/ml) in protein-free HBSS buffered with $25 \mathrm{mM}$ Hepes $(\mathrm{pH}$ 7.4), ${ }^{111} \mathrm{In}(5 \mu \mathrm{Ci} / \mathrm{ml})$ was added, and the cell suspension was incubated at room temperature for $15 \mathrm{~min}$. The cells were then diluted two- to fivefold with cold HBSS containing $25 \mathrm{mM}$ Hepes and $0.5 \%$ BSA or $10 \%$ FCS to quench the labeling reaction; pelleted, resuspended in the same medium, and incubated for an additional $20 \mathrm{~min}$ at $4^{\circ} \mathrm{C}$ (PMN) or room temperature (monocyte and cell line preparations). The cells were again pelleted and then resuspended in their respective assay media (see below).

Cytokine preparations and cell treatments. Human IL-1, isolated as $a \simeq 17,000$-mol wt polypeptide(s) from the supernatant of Staphylococcus albus-stimulated human monocytes by immunoabsorption (42) and Sephadex chromatography, was obtained from Genzyme Inc., Boston, MA. This material was provided in sterile $0.15 \mathrm{M} \mathrm{NaCl}$ with $5 \%$ FCS ("IL-1 diluent") and was reported to contain $100 \mathrm{U} / \mathrm{ml}$ thymocyte co-stimulation activity, $<1.0 \% \mathrm{~T}$ cell growth factor, $<1 \mathrm{U} / \mathrm{ml}$ interferon, and undetectable endotoxin activity. Thymocyte co-stimulation activity was independently confirmed (courtesy of Dr. C. Reiss, Dana-Farber Cancer Institute) and the absence of endotoxin $(<0.1 \mathrm{ng} / \mathrm{ml})$ documented by Limulus assay (Sigma Chemical Co.) in our laboratory. Human interleukin 2 (IL-2), isolated from Jurkat cell lines, was obtained from Genzyme Inc. in sterile normal saline at a final concentration of $5000 \mathrm{U} /$ $\mathrm{ml}$, and recombinant human IL-2 (Escherichia coli-derived) was provided by Biogen Inc., Cambridge, MA. Affinity purified human gamma-interferon $\left(0.6 \times 10^{6} \mathrm{U} / \mathrm{ml}\right)$, isolated from lectin-stimulated leukocytes, was obtained from Interferon Sciences, Inc. (New Brunswick, NJ) and recombinant gamma-interferon (cloned Chinese hamster ovary cell linederived) was kindly provided by W. Fiers (State University of Ghent, Belgium).

Cultured cell monolayers were washed three times with pretreatment media (see below), incubated for up to $60 \mathrm{~min}$ at $37^{\circ} \mathrm{C}$, and washed again prior to the treatment with cytokines. IL-1, control media (IL-1 diluent, Genzyme, or 5\% FCS-RPMI), or other lymphokine preparations were added to each $16-\mathrm{mm}$ well in a final volume of $0.5 \mathrm{ml}$ of pretreatment media. Several pretreatment media including RPMI-10\% FCS, RPMI$0.1 \%$ BSA, and Tyrodes' $-0.1 \%$ BSA were tested and produced comparable results. After incubation $\left(37^{\circ} \mathrm{C}, 5 \% \mathrm{CO}_{2}\right)$ for up to $28 \mathrm{~h}$, each well was prepared for a leukocyte-monolayer adhesion assay. Selective IL-1 pretreatment of leukocyte suspensions was performed in an analogous fashion.

In certain experiments, cycloheximide $(10 \mu \mathrm{g} / \mathrm{ml})$, actinomycin D $(5 \mu \mathrm{g} / \mathrm{ml})$ (Sigma Chemical Co.), or acetylsalicylic acid (100 $\mu \mathrm{M}$, Fisher Scientific Co., Medford, MA) were added to the endothelial cultures 30 min prior to the addition of IL- 1 and allowed to remain in the medium throughout the pretreatment phase. In pilot experiments, this concentration of cycloheximide blocked $>97 \%$ of $\left[{ }^{35}\right.$ S $]$ methionine incorporation into endothelial monolayers. In other experiments, hirudin $(5 \mathrm{U} / \mathrm{ml}$, grade IV, Sigma Chemical Co.) was added during the pretreatment phase and/or during the monolayer adhesion assay. This amount of hirudin was calculated to be sufficient (unit for unit) to inhibit the IL-1-induced endothelial cell procoagulant activity (32).

Leukocyte-monolayer adhesion assay. The adhesion of washed human leukocytes, leukocyte cell lines, and erythrocytes to cultured cells or noncellular surfaces was measured using quantitative monolayer adhesion assays, similar to those previously described by our laboratory $(15,38)$. Test wells (16-mm diam) containing confluent endothelial monolayers on Thermanox coverslips were washed three times and then incubated with $0.5 \mathrm{ml}$ of unlabeled or radiolabeled blood cell suspensions, for defined periods varying from 10 to $60 \mathrm{~min}$ at $37^{\circ} \mathrm{C}$, under static conditions, in their respective assay media (Tyrodes- $0.1 \%$ BSA for PMN 
and erythrocytes, RPMI-0.1\% BSA for monocytes, RPMI-1\% FCS for HL-60 cells and U937 cells). Typically, the blood cell concentrations were $5.0 \times 10^{6} / \mathrm{ml}$ for PMN and erythrocytes, $4.0 \times 10^{5}$ for monocytes, and $2.0 \times 10^{6}$ for HL-60 cells and U937 cells. In pilot experiments, DNAse (up to $20 \mathrm{U} / \mathrm{ml}$, Worthington Diagnostic Systems Inc., Freehold, $\mathrm{NJ}$ ) was added during the adhesion assay in an attempt to minimize nonspecific adhesive effects of nuclear debris released from disrupted cells. This DNAse treatment had no significant effect and, therefore, was not routinely used. At the end of the assay incubation, the endothelial monolayers were subjected to a standardized wash procedure to remove unbound blood cells (43). Typically, monolayers on Thermanox coverslips were washed by repeated passage (three times) through the airfluid interphase of a $250-\mathrm{ml}$ beaker containing assay media or HBSS with calcium and magnesium (M. A. Bioproducts). In the case of unlabeled blood cells, the number bound per square millimeter was determined by direct microscopy. One randomly selected central field and four peripheral fields of intact endothelial monolayers were examined with an ocular grid using phase-contrast microscopy $(\times 200)$ for unstained cells, and light microscopy $(\times 400)$ for stained (Wright-Giemsa, nonspecific esterase and immunoperoxidase) preparations. The number of adherent ${ }^{111}$ In-labeled leukocytes was determined from the monolayer bound radioactivity and the specific activity (counts per minute/cell) of the blood cell preparations using a Gamma Counter (Beckman Instruments, Inc.). Pilot experiments indicated that visual and radiometric methods gave comparable results, and that the "III-labeling procedure did not significantly alter the adhesive characteristics of the blood cells. Experiments using " In-labeled leukocytes routinely included morphologic monitoring of at least one well from each experimental group in order to assess the intactness of the endothelial monolayer and the nature of the endothelial-leukocyte interaction.

\section{Results}

Basal adhesion of PMN and monocytes to human endothelial monolayers. Under basal conditions (i.e., in the absence of any added stimuli), $149 \pm 13$ PMN (1.2\% of total added) adhered per $\mathrm{mm}^{2}$ of cultured human endothelial cell monolayer in a standardized 10-min adhesion assay (mean \pm SEM, 16 experiments) (Fig. $1 \mathrm{~A}$ ). At the end point of these relatively short incubations, the majority ( $>90 \%$ ) of the PMN were individually attached to the top surface of the endothelial monolayer with little evidence of transendothelial migration upon microscopic examination (38) (Fig. $2 A$ ).

Incubation of human peripheral blood monocytes, isolated by density centrifugation, with confluent endothelial monolayers for $10 \mathrm{~min}$ resulted in the adhesion of $112 \pm 8$ leukocytes $/ \mathrm{mm}^{2}$ (mean \pm SEM, 11 experiments; $11.2 \%$ of total added). Longer incubation periods (30-60 $\mathrm{min}$ ) resulted in increased monocyte adhesion and increased spreading of adherent monocytes on the endothelial monolayer. Similar results were obtained with monocytes isolated by counterflow centrifugation elutriation. The endothelial-adherent monocytes were esterase positive and were recognized by the antimonocyte monoclonal antibody MO2. Small numbers of lymphocytes (esterase negative, T11-antigen positive), which contaminated the monocyte preparations, also adhered to the endothelial monolayers. In these experiments, both PMN (Fig. $2 A$ ) and monocytes interacted with the surface of intact endothelial monolayers without aggregation and without causing endothelial damage, as evidenced by cell retraction or detachment.

IL-1 treatment of human endothelial monolayers increases leukocyte adhesion. Having defined PMN and monocyte adhesion to endothelial monolayers under basal conditions, we then examined the effect of IL-1 on endothelial cell surface adhesivity. Pretreatment of human endothelial monolayers for $4 \mathrm{~h}$ with 5 $\mathrm{U} / \mathrm{ml}$ of IL-1 resulted in an $18.3 \pm 2.6$-fold increase in the adhesion of human PMN leukocytes during subsequent 10-min leukocyte-monolayer adhesion assays (mean \pm SEM, 16 experiments; 12 blood donors; $P<0.0005$, Student's $t$ test, two tail) (Fig. $1 A$ ). In addition, human monocytes isolated by density gradient centrifugation demonstrated a $2.6 \pm 0.3$-fold increase in adhesion to IL-1-treated HEC monolayers over basal levels in 10-min adhesion assays (seven experiments; four blood donors, $P<0.005$ ) (Fig. $1 B$ ). Comparable results were obtained with monocytes isolated by counterflow centrifugation elutriation (data not shown). Quantitatively similar effects of IL-1 on endothelial adhesivity for both PMN and monocytes were observed with longer adhesion assay periods (up to $1 \mathrm{~h}$ ). In contrast to the effect produced by endothelial pretreatment with IL-1, the addition of IL-1 during the adhesion assay itself did not significantly alter PMN or monocyte attachment (Fig. $1 A$ and $B$ ). Furthermore, pretreatment of the PMN or monocytes with IL$1(5 \mathrm{U} / \mathrm{ml})$ for periods from $10 \mathrm{~min}$ to $1 \mathrm{~h}$ did not significantly promote their adhesion to untreated endothelial monolayers (data not shown). In addition, the presence of conditioned medium from IL-1-treated ( $5 \mathrm{U} / \mathrm{ml}, 4 \mathrm{~h}$ ) HEC monolayers did not stimulate PMN or monocyte adhesion to untreated HEC monolayers during the standard adhesion assays. IL-1-treated endothelial monolayers did not show evidence of cell retraction or
A. PMN LEUKOCYTES

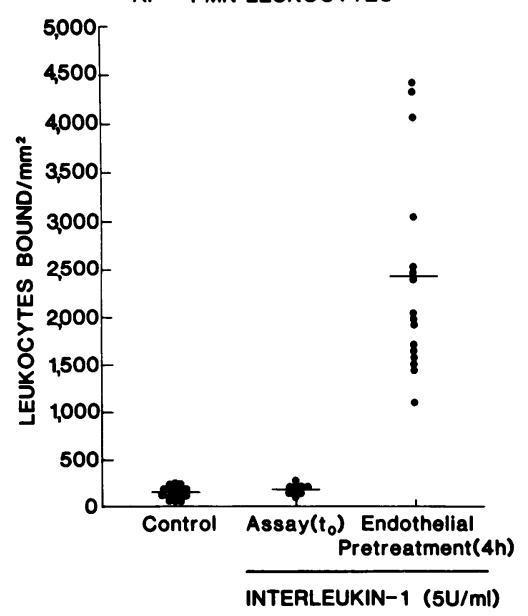

B. MONOCYTES

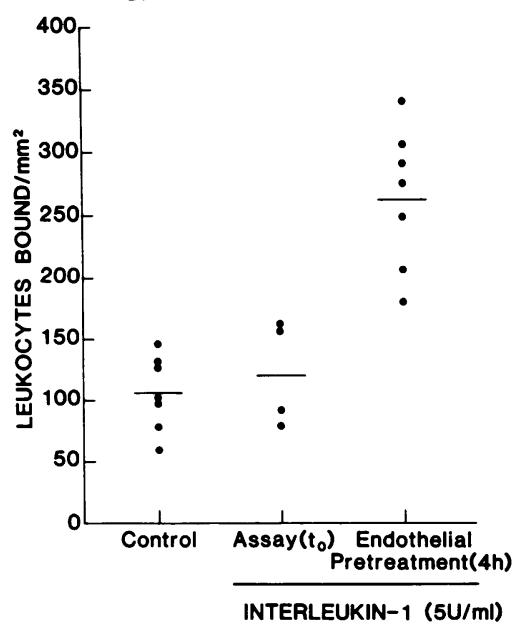

Figure 1. Effect of IL-1 on the adhesion of human PMN leukocytes $(A)$ and monocytes $(B)$ to cultured human endothelial monolayers. Confluent HEC monolayers (passage levels 2-4) were incubated for $4 \mathrm{~h}$ at $37^{\circ} \mathrm{C}$ with control or IL-1 ( 5 $\mathrm{U} / \mathrm{ml}$ ) containing pretreatment media (Methods) and then washed prior to the start of the leukocyte-monolayer adhesion assays. ${ }^{111}$ In-labeled PMN $\left(5.0 \times 10^{6} / \mathrm{ml}\right)$, or monocytes $\left(4.0 \times 10^{5} /\right.$ $\mathrm{ml}$ ), were added to the wells in $0.5 \mathrm{ml}$ of assay media (Methods) and incubated for $10 \mathrm{~min}$ at $37^{\circ} \mathrm{C}$. IL-1 $(5 \mathrm{U} / \mathrm{ml})$ was added at the start of the monolayer adhesion assay to one set of replicate wells (Assay, $t_{0}$ ). Each symbol represents the mean of triplicate determinations in a given experiment and the horizontal lines represent the overall mean for each experimental group. 


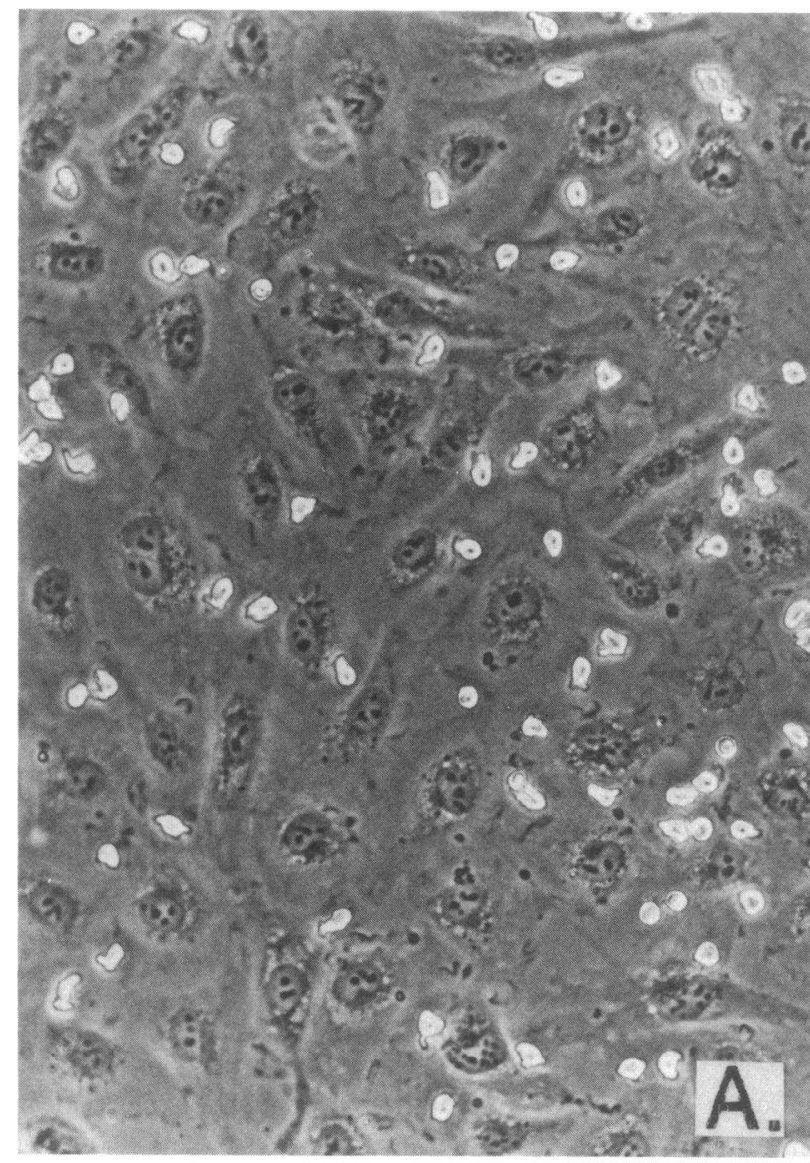

Figure 2. Phase-contrast photomicrographs $(\times 200)$ of the adhesion of human polymorphonuclear leukocytes to control $(A)$ and IL-1-treated

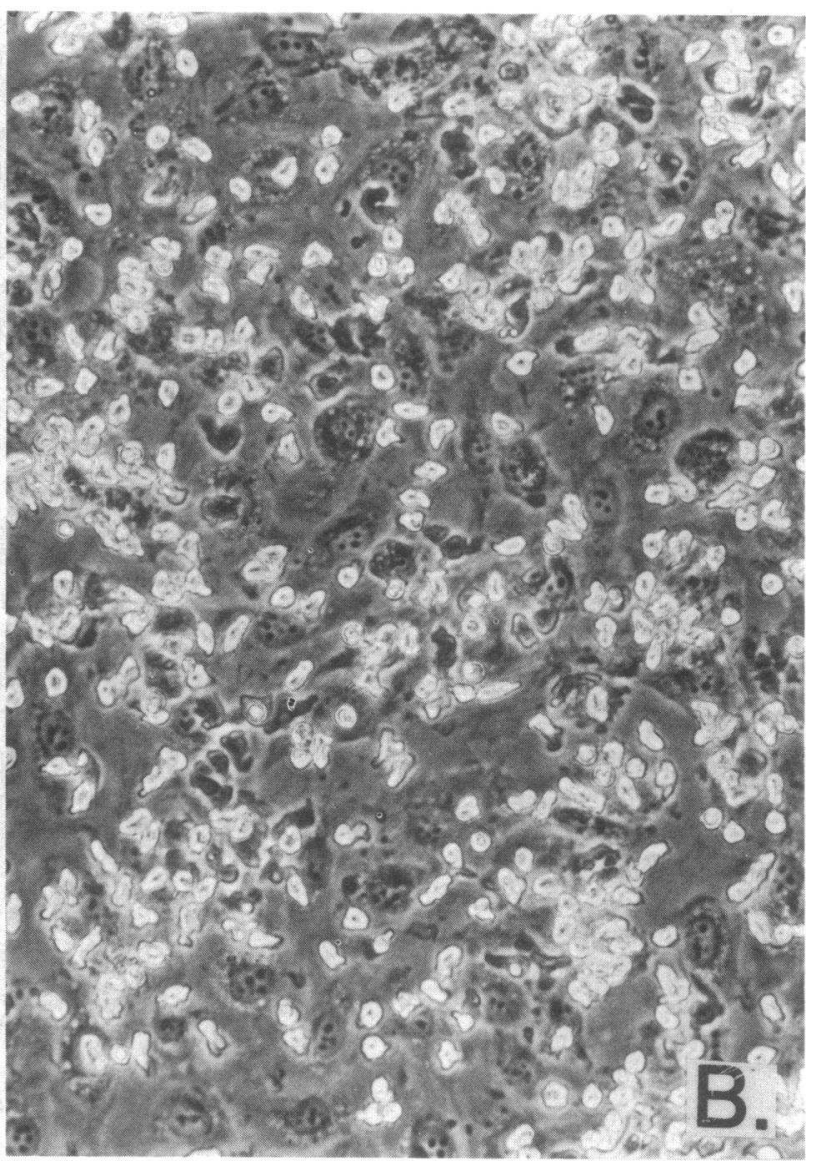

$(5 \mathrm{U} / \mathrm{ml}, 4 \mathrm{~h})(B)$ human endothelial monolayers (passage level 2$)$ at the end of a 10-min monolayer adhesion assay. detachment by phase-contrast or light microscopy, and the leukocytes appeared to be attached relatively uniformly across the surface of the monolayer (Fig. $2 \mathrm{~B}$ ).

Washed ${ }^{111}$ In-labeled human erythrocytes demonstrated little adhesion to confluent HEC monolayers (16 \pm 3 erythrocytes/ $\mathrm{mm}^{2}$, mean $\pm \mathrm{SEM}$, three experiments). Neither IL-1 treatment of the endothelial monolayers nor the presence of IL-1 during the adhesion assay significantly altered erythrocyte attachment (14 \pm 4 and $15 \pm 3$ erythrocytes $/ \mathrm{mm}^{2}$, respectively, three experiments).

Adhesion characteristics of the monocytelike cell line U937 and the promyelocytic cell line $H L-60$. We also examined endothelial-leukocyte adhesion using the human promyelocytic cell line HL-60 and the human monocytelike cell line U937. Unlike PMN and monocytes, HL-60 cells and U937 cells are generally considered "nonadherent" $(44,45)$, and under our standard assay conditions, they demonstrated little or no attachment to tissue culture plastic or glass surfaces ( < five cells/ $\left.\mathrm{mm}^{2}\right)$. However, as we have previously reported $(33,46), \mathrm{U} 937$ cells do adhere extensively to primary cultures of human endothelial cells $\left(\simeq 1,000 / \mathrm{mm}^{2}\right)$. Passaged HEC monolayers (passage levels 2-20) consistently demonstrated lower levels of basal U937 cell adhesion $\left(297 \pm 32\right.$ cells $/ \mathrm{mm}^{2}$, mean \pm SEM, 32 experiments) than did primary HEC cultures, whereas monolayers of SV40-transformed human endothelial cells (SV-HEC-F) showed negligible U937 adhesion $\left(<40\right.$ cells $/ \mathrm{mm}^{2}$ ). We also examined adhesion of promyelocytic HL-60 cells to several cultured cell types and found that passaged HEC, SV40-transformed HEC, and bovine aortic endothelial cells demonstrated relatively low basal adhesivity for this leukocyte cell line $\left(40-200 / \mathrm{mm}^{2}\right)$.

The minimal reactivity exhibited by $\mathrm{U} 937$ and HL-60 cells for noncellular components (e.g., plastic coated with FCS) allowed us to utilize these cell lines to focus directly on the cellcell interactions involved in leukocyte-endothelial adhesion assays. U937 cell adhesion to primary cultures of human endothelium was maintained ( $>90 \%$, three experiments) after endothelial cell fixation with paraformaldehyde $\left(2 \%, 3 \mathrm{~min}, 4^{\circ} \mathrm{C}\right)$, but was abolished (85-95\% decrease, three experiments) by subsequent mild proteolysis with $n$-tosyl-L-phenylalanine chloromethyl ketone trypsin (Millipore Corporation, Freehold, NJ, $13.5 \mathrm{U} / \mathrm{ml}, 15 \mathrm{~min})$. These experiments suggested that endothelial cell-associated protein(s) are involved in U937 cell attachment, and that active endothelial metabolism is not required during the adhesion event.

Similar to the results obtained with peripheral blood leukocytes (Fig. 1), IL-1 pretreatment ( $5 \mathrm{U} / \mathrm{ml}, 4 \mathrm{~h}$ ) of passaged endothelial monolayers resulted in a $33.0 \pm 6$-fold increase in HL-60 cell adhesion (mean \pm SEM, six experiments) and a $4.9 \pm 0.5$-fold increase in U937 cell adhesion (15 experiments) over basal levels. The presence of IL-1 during the assay did not significantly alter either HL-60 or U937 cell adhesion to endothelium (Fig. 3). Pretreatment of these leukocyte cell lines with the same concentration of IL-1 for $4 \mathrm{~h}$ did not increase their adhesion to untreated endothelial monolayers (Fig. 3). In ad- 

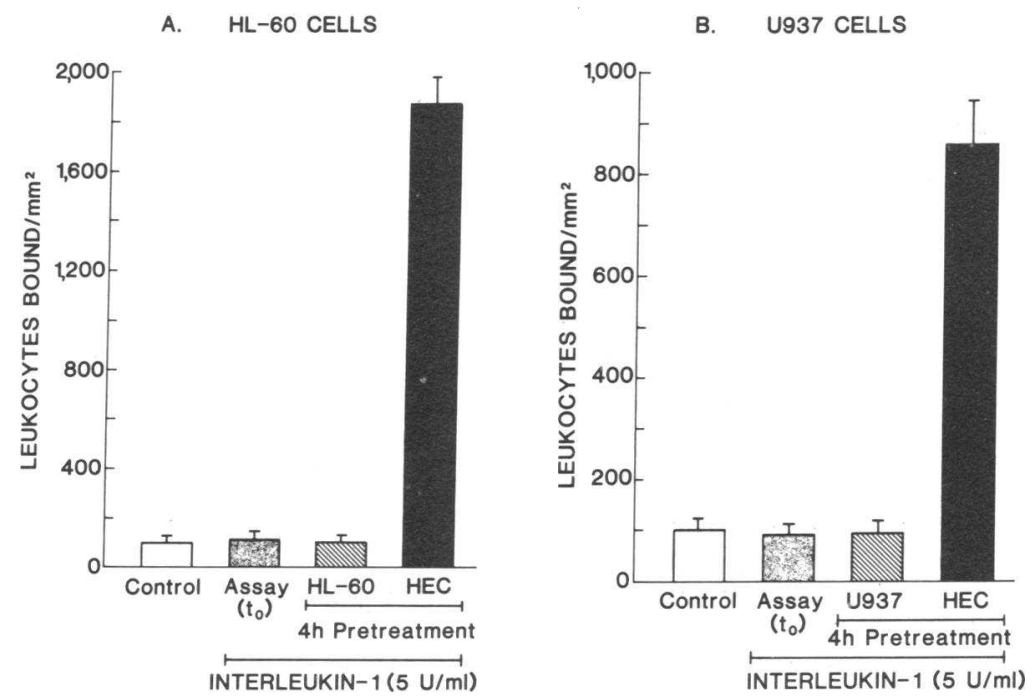

Figure 3. Effect of IL-1 on the adhesion of HL-60 cells $(A)$ and $U 937$ cells $(B)$ to cultured human endothelial monolayers (passage level 3). Confluent HEC monolayers (solid bars) or the leukocyte cell lines HL-60 and U937 (hatched bars), were selectively pretreated with IL$1\left(5 \mathrm{U} / \mathrm{ml}, 4 \mathrm{~h}, 37^{\circ} \mathrm{C}\right)$ in RPMI-10\% FCS and washed prior to a 30-min leukocyte-monolayer adhesion assay $\left(2.0 \times 10^{6}{ }^{111}\right.$ In-labeled leukocytes $/ \mathrm{ml}, 0.5 \mathrm{ml}$ per well $)$. At the start of the adhesion assay, IL-1 $(5 \mathrm{U} / \mathrm{ml})$ was added to one set of wells (Assay, $t_{0}$, stippled bar). Basal adhesion is shown by open bar (Control). Each bar represents the mean $\pm \mathrm{SD}$ of triplicate wells in a single experiment. Similar results were obtained in three additional experiments. dition, the adhesion of paraformaldehyde fixed $\left(2 \%, 5 \mathrm{~min}, 4^{\circ} \mathrm{C}\right)$ HL-60 cells to control and IL-1-treated HEC monolayers was comparable to that of unfixed HL-60 cells.

Characterization of the IL-1 effect on endothelial-leukocyte adhesion. As shown in Fig. 4 with U937 cells, increased leukocyte adhesion to endothelial monolayers was observed with $1 \mathrm{U} / \mathrm{ml}$ of IL-1 and a maximum effect was obtained with $5-20 \mathrm{U} / \mathrm{ml}$. Incubation of the monolayers with $5 \mathrm{U} / \mathrm{ml}$ of IL-1 resulted in a rapid rise in adhesivity of blood leukocytes and the cell lines which peaked by 4-6 h. During longer (12-24 h) continuous incubations with IL-1, the monolayers demonstrated declining adhesivity and appeared to be hyporesponsive when rechallenged with fresh IL-1. However, as seen in Fig. 5, monolayers that had been treated for $4 \mathrm{~h}$ with IL-1, washed, and then incubated in the absence of IL-1 for $16 \mathrm{~h}$ could be fully restimulated with fresh IL-1 as demonstrated by HL-60 and U937 cell adhesion.

The continuous presence of cycloheximide $(10 \mu \mathrm{g} / \mathrm{ml})$ or actinomycin D $(5 \mu \mathrm{g} / \mathrm{ml})$ during IL-1 pretreatment of the en-

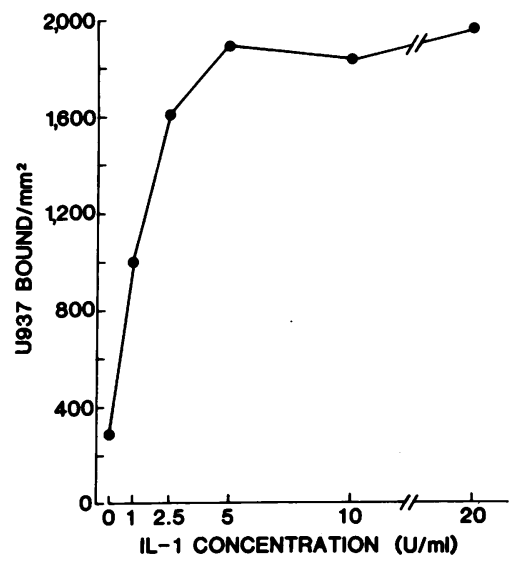

Figure 4. Concentration dependence of IL-1 stimulation of endothelial-U937 cell adhesion. Confluent HEC monolayers (passage level 8) were pretreated for $4 \mathrm{~h}$ at $37^{\circ} \mathrm{C}$ with increasing concentrations of IL-1 and washed prior to the addition of ${ }^{111}$ In-labeled U937 cells $\left(2.0 \times 10^{6}\right.$ cells $/ \mathrm{ml}, 0.5 \mathrm{ml}$ ) for a $1-\mathrm{h}$ leukocyte-monolayer adhesion assay. Each point represents mean values of triplicate determinations. Similar results were obtained with two additional experiments. dothelial monolayers significantly inhibited their development of increased adhesivity for leukocytes (Table I). These experiments suggest that the IL-1 effect on endothelium depended, at least in part, on de novo protein synthesis. Acetylsalicylic acid $(100 \mu \mathrm{M})$ added during pretreatment of the endothelium did not significantly alter IL-1-induced PMN or monocyte adhesion ( $93 \pm 14$ and $86 \pm 24 \%$ of IL-1-treated monolayers, respectively, mean $\pm \mathrm{SD}$, three experiments), thus ruling out a primary role for cyclooxygenase products of arachidonic acid metabolism in mediating this IL-1 effect. Because we have found previously that IL-1 can induce the expression of a tissue factorlike procoagulant activity on human endothelial cells $(32,33)$, which could potentially initiate generation of thrombin (and other procoagulant activities) in our system, we examined the effect of hirudin, a potent thrombin antagonist. The addition of hirudin ( $5 \mathrm{U} / \mathrm{ml}$ ), during the IL-1 pretreatment phase, and/or the leukocyte-monolayer adhesion assay itself, did not significantly alter HL-60 and U937 cell adhesion (data not shown). IL-1 stimulation of endothelial-leukocyte adhesion did not appear to re-

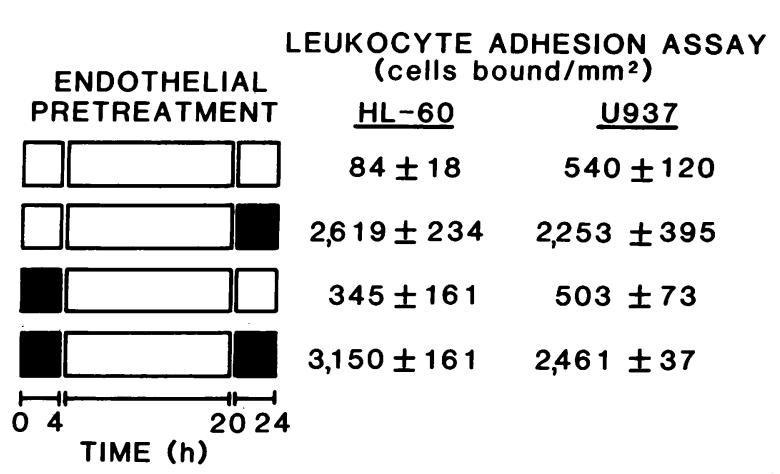

Figure 5. Reversibility of the IL-1 effect on endothelial-leukocyte adhesion. Cultured human endothelial monolayers were incubated for $4 \mathrm{~h}$ in control (RPMI-10\% FCS) (open bar) or in IL-1 $(5 \mathrm{U} / \mathrm{ml})$ containing media (solid bar), washed, incubated an additional $16 \mathrm{~h}$ in the absence of IL-1, and then rechallenged for $4 \mathrm{~h}$ with control or IL-1 containing $(5 \mathrm{U} / \mathrm{ml})$ media. At the end of this pretreatment period, a standard 30-min monolayer adhesion assay was performed with HL60 cells or U937 cells $\left(2.0 \times 10^{6} / \mathrm{ml}\right)$. Data represents mean $( \pm \mathrm{SD})$ of triplicate determinations in separate experiments. 
Table I. Cycloheximide and Actinomycin D Effects on IL-1-stimulated Endothelial-Leukocyte Adhesion*

\begin{tabular}{llc}
\hline & \multicolumn{2}{l}{ Percent inhibition of IL-1-stimulated adhesion $\ddagger$} \\
\cline { 2 - 3 } Leukocyte cell type & Cycloheximide treatment & Actinomycin D treatment \\
\hline PMN & $85 \pm 7$ & $95 \pm 5$ \\
Monocytes & $81 \pm 9$ & $122 \pm 7$ \\
HL-60 Cells & $85 \pm 8$ & $89 \pm 5$ \\
U937 Cells & $77 \pm 6$ & $76 \pm 8$ \\
\hline
\end{tabular}

* Cycloheximide $(10 \mu \mathrm{g} / \mathrm{ml})$ or actinomycin $\mathrm{D}(5 \mu \mathrm{g} / \mathrm{ml})$ was added to confluent HEC monolayers in $0.5 \mathrm{ml}$ of pretreatment media (see Methods). $30 \mathrm{~min}$ later $25 \mu \mathrm{l}$ of IL-1 ( $5 \mathrm{U} / \mathrm{ml}$ final concentration), or an appropriate control medium, was added and the cultures incubated for an additional $4 \mathrm{~h}$ at $37^{\circ} \mathrm{C}$. The endothelial monolayers were washed, and ${ }^{111}$ In-labeled PMN $\left(5.0 \times 10^{6} / \mathrm{ml}\right)$, monocytes $\left(4.0 \times 10^{5} /\right.$ $\mathrm{ml})$, HL-60 cells $\left(2.0 \times 10^{6} / \mathrm{ml}\right)$, or U937 cells $\left(2.0 \times 10^{6} / \mathrm{ml}\right)$ were added in $0.5 \mathrm{ml}$ of their respective assay media for a $10-\mathrm{min}$ (PMN and monocytes) or a 30-min (HL-60 and U937) adhesion assay. Replicate endothelial monolayers were treated with the carrier for actinomycin $\mathrm{D}(0.1 \%$ dimethyl sulfoxide) without significant effect on control or IL-1-induced leukocyte adhesion (data not shown).

$\ddagger$ Percent inhibition was calculated as 100 -[(IL-1-stimulated adhesion "treated group"/IL-1-stimulated adhesion "untreated group") $\times 100]$. The data represent the mean \pm SEM of three separate experiments for each leukocyte type.

quire the continued presence of a soluble endothelial-derived mediator(s), inasmuch as the conditioned media was routinely removed, and the cultures were washed, prior to the beginning of the leukocyte-monolayer adhesion assay. In separate experiments, the transfer of conditioned media from IL-1-stimulated ( $5 \mathrm{U} / \mathrm{ml}, 4 \mathrm{~h}$ ) HEC cultures to control cultures, for the period of the adhesion assay (10 or $30 \mathrm{~min}$ ), did not augment HL-60 cell or U937 cell adhesion. IL-1 treatment of endothelial monolayers did not result in cell disruption or death, as assessed by phase-contrast microscopy, trypan blue exclusion (96-103\% of control, 10 experiments) or a radioactive cytotoxicity assay (47) ( -7 to $4 \%$ specific release, two experiments).
Pretreatment $\left(4 \mathrm{~h}, 37^{\circ} \mathrm{C}\right)$ of human endothelial monolayers with leukocyte-derived or recombinant IL-2 $(1-1,000 \mathrm{U} / \mathrm{ml})$, or gamma-interferon $(1-1,000 \mathrm{U} / \mathrm{ml})$, did not significantly increase HL-60 cell adhesion (75-108\% and $92-124 \%$ of control, respectively, two experiments). Similarly, in a single experiment, natural IL-2 and recombinant gamma-interferon did not affect endothelial-PMN adhesion (data not shown). Pretreatment of human endothelial monolayers for $4 \mathrm{~h}$ with endotoxin (lipopolysaccharide $E$. coli 0111:B4, Difco Laboratories, up to 10 $\mu \mathrm{g} / \mathrm{ml}$ ) resulted in a modest enhancement of leukocyte adhesion as demonstrated with $U 937$ cells $(2.9 \pm 0.4$-fold mean \pm SEM, eight experiments) and HL- 60 cells ( $2.5 \pm 0.6$ fold, three experiments). The effect of IL-1 was distinguished from that of endotoxin in that the former was completely abolished by heat treatment $\left(80^{\circ} \mathrm{C}, 15 \mathrm{~min}\right)(98 \pm 4 \%$ decrease, mean $\pm \mathrm{SEM}$, three experiments), whereas the latter was heat stable $(0 \pm 3 \%$ decrease, three experiments).

We also examined the effect of IL- 1 on leukocyte adhesion to several other cultured cell types. As seen in Fig. 6, IL-1 treatment of SV40-transformed human umbilical vein endothelial cells, bovine aortic endothelial cells, or two strains of human dermal fibroblasts did not significantly augment HL-60 or U937 cell adhesion. However, three separate strains of endothelial cells isolated from adult human saphenous veins, when treated with IL-1 (5 U/ml, $4 \mathrm{~h}$ ), showed enhanced adhesion for PMN and HL-60 quantitatively comparable to that observed with umbilical vein endothelial cells.

\section{Discussion}

These studies were based on the premise that vascular endothelium plays an active role in the localization of circulating blood leukocytes at sites of inflammation in vivo. Specifically, we tested the hypothesis that soluble mediators generated during immune/ inflammatory reactions can act directly on endothelial cells to alter their functional surface properties and thereby enhance endothelial-leukocyte adhesion. We have shown previously that monocyte-derived IL-1 can induce the biosynthesis and cell surface expression of a tissue factorlike procoagulant activity in cultured human endothelial cells, thus potentially making them
A.

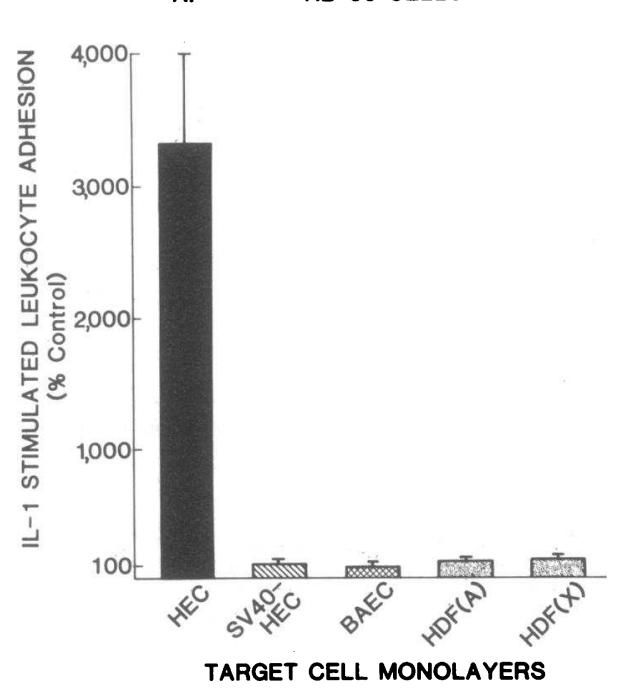

2008
B.

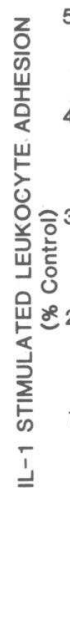

U937 CELLS

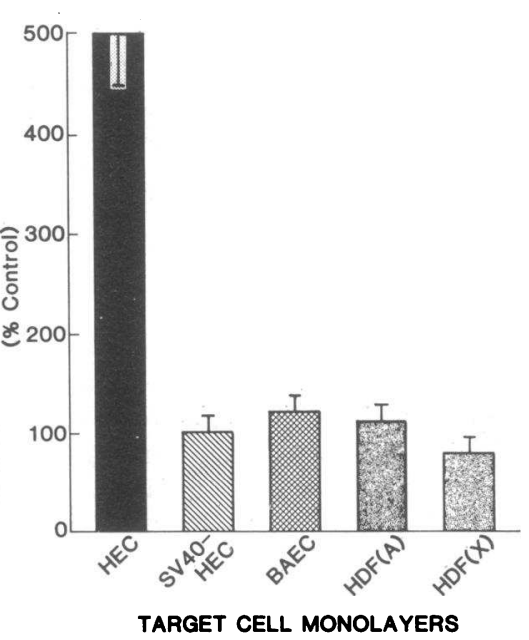

Figure 6. Target cell selectivity of the IL1 -stimulated leukocyte adhesion. Confluent monolayers of human endothelial cells (HEC), SV40-transformed HEC, bovine aortic endothelial cells (BAEC), and two strains of human dermal fibroblasts (HDF-A, HDF-X) were selectively pretreated for $4 \mathrm{~h}$ at $37^{\circ} \mathrm{C}$ with control (RPMI-10\% FCS) or IL-1 (5 U/ml) containing media and washed, and "11"In-labeled HL-60 cells $(A)$ or U937 $(B)(2.0$ $\left.\times 10^{6} / \mathrm{ml}, 0.5 \mathrm{ml} \mathrm{RPMI}-1 \% \mathrm{FCS}\right)$ were added for $\mathbf{3 0}$ min leukocyte-monolayer adhesion assays. The IL-1-stimulated leukocyte adhesion (\% of control) was calculated as [leukocytes bound $/ \mathrm{mm}^{2}$ to IL-1treated monolayers divided by leukocytes bound $/ \mathrm{mm}^{2}$ to control monolayers] $\times 100$. Each bar represents the mean ( \pm SEM) of data from three separate experiments for each cell type. 
actively thrombogenic $(32,33)$. We now report that IL-1 also can act directly on endothelium to alter its adhesivity for blood leukocytes. Selective endothelial pretreatment with IL-1 was found to increase significantly the adhesion of human polymorphonuclear leukocytes, monocytes, and the related cell lines HL-60 and U937. In contrast, selective leukocyte pretreatment with IL-1, or its presence during the adhesion assay, had no effect. The clear-cut endothelial selectivity of this IL-1 effect, and its magnitude, distinguish it from the action of other previously studied inflammatory mediators (reviewed in Reference 5). We propose that this endothelial-directed effect of IL-1 represents a new mechanism for the regulation of increased leukocyte adhesion at sites of inflammation.

The action of IL-1 on endothelial surface adhesivity for leukocytes was time dependent, reaching a peak at 4-6 h, and reversible. Inhibition of endothelial arachidonate metabolism via the cyclooxygenase pathway did not affect IL-1 stimulation of endothelial-leukocyte adhesion. In contrast, cycloheximide and actinomycin D did block the endothelial response to IL-1, suggesting a requirement for de novo protein synthesis.

The generation of a soluble mediator(s) by IL-1-treated endothelial monolayers did not appear to be essential for the augmentation of leukocyte adhesion, because the IL-1-stimulated endothelial cell-conditioned medium was routinely removed prior to the adhesion assay, and, in separate experiments, transfer of this conditioned medium to untreated endothelial monolayers did not promote leukocyte adhesion. Also, it appears unlikely that some alteration in the endothelial extracellular matrix is responsible for this IL-1 effect, because adhesion of HL-60 and U937 cells to the microexudate remaining after nonenzymatic removal of IL-1-treated confluent HEC monolayers was not increased compared to the adhesion observed with the microexudate from untreated monolayers (Bevilacqua, M. P., unpublished observation). Rather, the above results, as well as the topographical pattern of the adherent leukocytes, strongly suggest that an alteration in endothelial cell surface adhesivity is primarily involved. In support of this premise, we have identified several monoclonal antibodies that recognize IL-1-induced endothelial cell surface structures, and, in preliminary experiments, have found that certain of these antibodies substantially inhibit IL-1-induced HL-60 cell adhesion (48).

IL-1 stimulation of endothelial cell adhesivity for leukocytes was observed with human PMN, monocytes, HL-60 cells, and U937 cells. In addition, peripheral blood lymphocytes also adhere more extensively to IL-1-treated endothelial cultures (Bevilacqua, M. P., unpublished observations). In contrast, erythrocytes and unstimulated gel-filtered platelets (Wheeler, M. E., unipublished observations) interacted equally with control and IL-1treated HEC monolayers. The latter results indicate that the IL1 effect on leukocyte adhesion is not due to a nonspecific alteration in the endothelial cell membrane (e.g., net surface charge). The enhanced binding of several leukocyte types suggests at least two possibilities concerning the mechanisms of IL-1-stimulated endothelial-leukocyte adhesion. First, IL-1-treated endothelium may express multiple, distinct binding sites that are specific for each of the major classes of blood leukocytes, PMN, monocytes, and lymphocytes. Second, the IL-1 altered endothelial surface may be recognized by leukocyte surface molecule(s) that are shared in common by PMN, monocytes, and lymphocytes. Certain leukocyte cell surface-associated molecules have been implicated in adhesive interactions $(47,49-53)$. However, the possible role of these structures in leukocyte adhesion to IL-1-stim- ulated endothelium remains to be defined. Regardless of their precise nature, it appears that the putative leukocyte-associated recognition mechanism(s) for IL-1-treated endothelium are not present on two other blood elements, platelets (unstimulated) and erythrocytes, which interact similarly with control and IL1-treated endothelium.

IL-1 stimulation of endothelial-leukocyte adhesion shares many characteristics with IL-1 induction of endothelial procoagulant activity, as previously described by our laboratory (32, 33). These two inducible alterations exhibit similar concentration dependencies ( $1 \mathrm{U} / \mathrm{ml}$ threshold; 5-10 $\mathrm{U} / \mathrm{ml}$, maximum) and kinetic patterns (peak activity, 4-6 h). In addition, the expression of both of these activities is blocked by cycloheximide or actinomycin D treatment. It is possible that these two IL-1 inducible alterations in functional surface properties of endothelial cells are related; however, at least two lines of evidence suggest that they are distinct. First, extensive adhesion of U937 cells and normal monocytes is observed with unstimulated primary cultures of human umbilical vein endothelium $(33,46)$, which express little or no procoagulant activity (32); conversely, there is relatively little adhesion of U937 cells to SV40-transformed human endothelial cells, which constitutively express large amounts of procoagulant activity (Bevilacqua, M. P., unpublished observations). Second, our preliminary experiments indicate that IL1-induced endothelial procoagulant activity, but not endothelialU937 cell adhesion, can be blocked by a polyclonal antiserum to human apoprotein III (kindly provided by H. Prydz, University of Oslo, Oslo, Norway) (Bevilacqua, M. P., unpublished observations). In addition, hirudin did not significantly alter IL1 stimulation of endothelial-leukocyte adhesion, thus suggesting that the generation of thrombin was not essential for this effect. Further understanding of the mechanisms of endothelial-leukocyte adhesion and definition of the IL-1-induced endothelial cell structures may allow clarification of the relationship between IL-1 induced endothelial procoagulant activity and leukocyte adhesion.

The localized adhesion of leukocytes to the vessel wall at sites of inflammation is a complex event potentially involving multiple humoral stimuli and cellular components. Historically, it has been a matter of controversy whether leukocyte adhesion to the vascular lining during inflammation depends primarily on alterations in the leukocytes or in the endothelium (5). Our observations indicate that IL-1 can act on vascular endothelium to alter its functional surface properties related to leukocyte adhesion. The magnitude and endothelial selectivity of this effect suggest its importance as a localizing mechanism for leukocytevessel wall interactions in vivo. Recent data suggest that the endothelium itself is capable of producing IL-1-like activities $(25,26)$, and thus under certain pathophysiologic conditions, may act as both a source and a target of this important mediator. In addition, it is worth emphasizing that IL-1 represents a family of related molecules and thus several of its biological functions may actually involve distinct molecular species $(27-31,54)$.

In summary, we have demonstrated that the soluble mediator IL-1 acts selectively upon cultured human endothelial cells to augment their adhesivity for human leukocytes. Further studies are in progress to define the molecular basis of the endothelial cell surface alteration involved in this IL-1 action (48). Our data strongly support the hypothesis that the vascular lining can play an active role in the localized adhesion and efflux of blood leukocytes in vivo, and implicate the inflammatory mediator IL-1 as a potent modulator of this endothelial function. 
Note added in proof: Lysates of murine L cells expressing a recombinant human IL-1 species (kindly provided by Dr. Livelli, Cistron Technology, Pine Brook, NJ [30]) induced endothelial adhesivity for PMN and HL60 cells comparable to that obtained with human monocyte-derived IL1 preparations.

\section{Acknowledgments}

We gratefully acknowledge the expert assistance of Gerard Majeau and Anne Brock in the adhesion studies, Kay Case and Ethel Gordon in cell culturing, and Crystal DeVance and Donna Hickey in the preparation of the manuscript. We also thank Drs. F. V. Lionetti and F. W. Luscinskas (Center for Blood Research, Boston, MA) for their helpful advice in the application of counterflow centrifugation elutriation techniques in our laboratory.

This research was supported by National Institutes of Health grants HL-22602 and T32-HL-07066. Dr. Jordan S. Pober is a Searle Scholar.

\section{References}

1. Allison, F., M. R. Smith, and W. B. Wood. 1955. Studies on the pathogenesis of acute inflammation. I. The inflammatory reaction to thermal injury as observed in the rabbit ear chamber. J. Exp. Med. 102: 655-668.

2. Marchesi, V. I., and H. W. Florey. 1960. Electron micrographic observations on the emigration of leukocytes. Q. J. Exp. Physiol. 45: 343-348.

3. Grant, L. 1973. The sticking and emigration of white blood cells in inflammation. In The Inflammatory Process. Vol. 2. B. Zweifach, L. Grant, and L. McCluskey, editors. Academic Press, Inc., New York. 205.

4. Wilkinson, P. C., and J. M. Lackie. 1979. The adhesion, migration, and chemotaxis of leukocytes in inflammation. Curr. Top. Pathol. 68: 48-88.

5. Harlan, J. M. 1985. Leukocyte-endothelial interactions. Blood. 65:513-525.

6. Gerrity, R. G. 1981. The role of the monocyte in atherogenesis. I. Transition of blood-borne monocytes into foam cells in the fatty lesions. Am. J. Pathol. 103:181-190.

7. Joris, I., T. Zand, J. J. Nunnari, F. J. Krolikowski, and G. Majno. 1983. Studies on the pathogenesis of atherosclerosis. I. Adhesion and emigration of mononuclear cells in the aorta of hypercholesterolemic rats. Am. J. Pathol. 113:341-358.

8. Faggiotto, A., R. Ross, and L. Harker. 1984. Studies of hypercholesterolemia in the nonhuman primate. I. Changes that lead to fatty streak formation. Arteriosclerosis. 4:323-340.

9. Faggiotto, A., and R. Ross. 1984. Studies of hypercholesterolemia in the nonhuman primate. II. Fatty streak conversion to fibrous plaque. Arteriosclerosis. 4:341-356.

10. Gimbrone, M. A., Jr., and M. R. Buchanan. 1982. Interactions of platelets and leukocytes with vascular endothelium. In vitro studies. Ann. NY Acad. Sci. 401:171-183.

11. Smith, R. P. C., J. M. Lackie, and P. C. Wilkinson. 1979. The effects of chemotactic factors on the adhesiveness of rabbit neutrophil granulocytes. Exp. Cell Res. 122:169-177.

12. Hoover, R. L., R. Folger, W. A. Haering, B. R. Ware, and M. J. Karnovsky. 1980. Adhesion of leukocytes to endothelium. Roles of divalent cations, surface charge, chemotactic agents and substrate. J. Cell Sci. 45:73-86.

13. Hoover, R. L., M. J. Karnovsky, K. F. Austen, E. J. Corey, and R. A. Lewis. 1984. $\mathrm{LTB}_{4}$ modulates neutrophil endothelial interactions. Proc. Natl. Acad. Sci. USA. 81:2191-2193.

14. Zimmerman, G. A., and H. R. Hill. 1984. Inflammatory mediators stimulate granulocyte adherence to cultured human endothelial cells. Thromb. Res. 35:203-217.

15. Gimbrone, M. A. Jr., A. F. Brock, and A. I. Schafer. 1984. Leu- kotriene $\mathrm{B}_{\mathbf{4}}$ stimulates polymorphonuclear leukocyte adhesion to cultured vascular endothelial cells. J. Clin. Invest. 74:1552-1555.

16. Tonnesen, M. G., L. A. Smedly, and P. M. Henson. 1984. Neutrophil-endothelial cell interactions: modulation of neutrophil adhesiveness induced by complement fragments C5a and C5a des arg and formylmethionyl-leucyl-phenylalanine in vitro. J. Clin. Invest. 74:1581-1592.

17. Charo, C. F., C. Yuen, and I. M. Goldstein. 1985. Adherence of human polymorphonuclear leukocytes to endothelial monolayers: effects of temperature, divalent cations, and chemotactic factors on the strength of adherence measured with a new centrifugation assay. Blood. 65:473479.

18. Harlan, J. M., B. R. Schwartz, M. A. Reidy, S. M. Schwartz, H. D. Ochs, and L. A. Harker. 1985. Activated neutrophils disrupt endothelial monolayer integrity by an oxygen radical-independent mechanism. Lab. Invest. 52:141-150.

19. Jauchem, J. R., M. Lopez, E. A. Sprague, and C. J. Schwartz. 1982. Mononuclear cell chemoattractant activity from cultured arterial smooth muscle cells. Exp. Mol. Pathol. 37:166-174.

20. Valente, A. J., S. R. Fowler, E. A. Sprague, J. L. Kelley, C. A. Suenram, and C. J. Schwartz. 1984. Initial characterization of a peripheral blood mononuclear cell chemoattractant derived from cultured arterial smooth muscle cells. Am. J. Pathol. 117:409-417.

21. Mazzone, T., M. Jensen, and A. Chatt. 1983. Human arterial wall cells secrete factors that are chemotactic for monocytes. Proc. Natl. Acad. Sci. USA. 80:5094-5097.

22. Mercandetti, A. J., T. A. Lane, and M. E. M. Colmerauer. 1984. Cultured human endothelial cells elaborate neutrophil chemoattractants. J. Lab. Clin. Med. 104:370-380.

23. DiCorleto, P. E., and D. F. Bowen-Pope. 1983. Cultured endothelial cells produce a platelet-derived growth factor-like protein. Proc. Natl. Acad. Sci. USA. 80:1919-1923.

24. Deuel, T. F., R. M. Senior, J. S. Huang, and G. L. Griffin. 1982. Chemotaxis of monocytes and neutrophils to platelet-derived growth factor. J. Clin. Invest. 69:1046-1049.

25. Warner, C. R., R. M. Vetto, and D. R. Burger. 1984. The mechanisms of antigen presentation by endothelial cells. Immunobiology. 168: 453-469.

26. Windt, M. R., and L. J. Rosenwasser. 1984. Human vascular endothelial cells produce interleukin-1. Lymphokine Res. 3:281a. (Abstr.)

27. Oppenheim, J. J., and I. Gery. 1982. Interleukin-1 is more than an interleukin. Immunol. Today. 34:113-119.

28. Lachman, L. B. 1983. Human interleukin-1: purification and properties. Fed. Proc. 42:2639-2645.

29. Dinarello, C. A. 1984. Interleukin-1. Rev. Infect. Dis. 6:51-95.

30. Auron, P. E., A. C. Webb, L. J. Rosenwasser, S. F. Mucci, A. Rich, S. M. Wolfe, and C. A. Dinarello. 1984. Nucleotide sequence of human monocyte interleukin-1 precursor cDNA. Proc. Natl. Acad. Sci. USA. 81:7907-7911.

31. Lomedico, P. T., U. Gubler, C. P. Hellman, M. Dukovich, J. G. Giri, Y. E. Pan, K. Collier, R. Saminow, A. O. Chua, and S. B. Mizel. 1984. Cloning and expression of murine interleukin-1 cDNA in Escherichia coli. Nature (Lond.). 312:458-462.

32. Bevilacqua, M. P., J. S. Pober, G. R. Majeau, R. S. Cotran, and M. A. Gimbrone, Jr. 1984. Interleukin-1 (IL-1) induces biosynthesis and cell surface expression of procoagulant activity in human vascular endothelial cells. J. Exp. Med. 160:618-623.

33. Bevilacqua, M. P., J. S. Pober, R. S. Cotran, and M. A. Gimbrone, Jr. 1985. Effects of mononuclear phagocytes and their secretory products on vascular endothelium. In Mononuclear Phagocytes. Characteristics; physiology, and function. R. Van Furth, editor. Martinus Nijhoff Publishers, Boston, Dordrecht, Lancaster. 747-752.

34. Gimbrone, M. A., Jr. 1976. Culture of vascular endothelium. Prog. Hemostasis Thromb. 3:1-28.

35. Thornton, S. C., S. W. Mueller, and E. M. Levine. 1983. Human endothelial cells: use of heparin in cloning and long-term serial cultivation. Science (Wash. DC). 222:623-625. 
36. Gimbrone, M. A., Jr., and G. C. Fareed. 1976. Transformation of cultured human vaseular endothelium by SV40 DNA. Cell. 9:685693.

37. Boyüm, A. 1968. Isolation of mononuclear cells and granulocytes from blood. Scand. J. Clin. Invest. 97(Suppl.):77-89.

38. Buchanan, M. R., M. J. Vazquez, and M. A. Gimbrone, Jr. 1983. Arachidonic acid metabolism and the adhesion of human polymorphonuclear leukocytes to cultured vascular endothelial cells. Blood. 62:889895.

39. Recalde, H. R. 1984. A simple method of obtaining monocytes in suspension. J. Immunol. Methods. 69:71-77.

40. Lionetti, F. J., S. M. Hunt, and C. R. Valeri. 1980. Isolation of human blood phagocytes by counterflow centrifugation elutriation. In Methods of Cell Separation. Vol. 3. N. Catsimpoolas, editor. Plenum Press, New York. 141-156.

41. Pinkus, G. S., and J. W. Said. 1985. Hodgkins disease, lymphocyte predominance type, nodular-A distinct entity? Am. J. Pathol. 118:1-6.

42. Rosenwasser, L. J., and C. A. Dinarello. 1981. Ability of human leukocyte pyrogen to enhance phytohemagglutinin induced murine proliferation. Cell Immunol. 63:134.

43. Curwen, K. D., H. Y. Kim, M. Vazquez, R. I. Handin, and M. A. Gimbrone, Jr. 1982. Platelet adhesion to cultured vascular endothelial cells. A quantitative monolayer adhesion assay. J. Lab. Clin. Med. 100:425-436.

44. Collins, S. J., R. C. Gallo, and R. E. Gallagher. 1977. Continuous growth and differentiation of human myeloid leukemia cells in suspension culture. Nature (Lond.). 270:347-349.

45. Sundstrom, C., and K. Nilsson. 1976. Establishment and characterization of a human histiocytic lymphoma cell line (U937). Int. J. Cancer. 17:565-577.

46. Bevilacqua, M. P., R. S. Cotran, G. R. Majeau, J. S. Pober, and
M. A. Gimbrone, Jr. 1984. Adhesion of human monocyte-like cell line (U937) to vascular endothelium. Fed. Proc. 43:459a. (Abstr.)

47. Collins, T., A. M. Krensky, C. Clayberger, W. Fiers, M. A. Gimbrone, Jr., S. J. Burakoff, and J. S. Pober. 1984. Human cytolytic T lymphocyte interactions with vascular endothelium and fibroblasts: role of effector and target cell molecules. J. Immunol. 133:1878-1884.

48. Bevilacqua, M. P., J. S. Pober, M. E. Wheeler, D. Mendrick, R. S. Cotran, and M. A. Gimbrone, Jr. 1985. Interleukin-1 (IL-1) acts on vascular endothelial cells to increase their adhesivity for blood leukocytes. Fed. Proc. 44:1494a. (Abstr.)

49. Gallitin, W. M., I. L. Weissman, and E. C. Butcher. 1983. A cell surface molecule involved in organ specific homing of lymphocytes. $\mathrm{Na}$ ture (Lond.). 304:30-34.

50. Springer, T. A., D. Davignon, M. K. Ho, K. Kurzinger, E. Martz, and F. Sanchez-Madrid. 1982. LFA-1 and Lyt-2,3 molecules associated with T lymphocyte-mediated killing; and Mac-1, an LFA-1 homologue associated with complement receptor function. Immunol. Rev. 68:171194.

51. Chin, Y., G. D. Carey, and J. J. Woodruff. 1983. Lymphocyte recognition of lymph node high endothelium. $\mathrm{V}$. Isolation of adhesion molecules from lysates of rat lymphocytes. J. Immunol. 131:1368-1374.

52. Buchanan, M. R., C. A. Crowley, R. E. Rosin, M. A. Gimbrone, Jr., and B. M. Babior. 1982. Studies on the interaction between GP-180deficient neutrophils and vascular endothelium. Blood. 60:160-164.

53. Harlan, J. M., P. D. Killen, F. Senecal, B. R. Schwartz, E. K. Yee, R. F. Taylor, P. G. Beatty, T. Price, and H. D. Ochs. 1985. The role of neutrophil membrane glycoprotein GP-150 in neutrophil adherence to endothelium in vitro. Blood. 66:167-178.

54. Barry, M. R., N. J. Woloski, and G. M. Fuller. 1985. Identification and partial characterization of hepatocyte-stimulating factor from leukemia cell lines: comparison with interleukin-1. Proc. Natl. Acad. Sci. USA. 82:1443-1447. 